\title{
Pretesting as Determinant of Attitude Change in Evaluation Research
}

\author{
Joh. Hoogstraten \\ University of Amsterdam
}

Two experiments were done to study the biasing effects of a pretest on subsequent posttest results. The problem of the first experiment was the evaluation of a programmed textbook used by psychology freshmen. It used a separate-sample pretest-posttest design and showed that a pretest containing mostly negative statements on programmed instruction confounded posttest results. The second experiment, using a different treatment, studied the pretest effects of positive or negative statements. The positive version counteracted the development of negative feelings towards the treatment. The negative version did not show a similar sensitizing effect. This was considered a consequence of the rather controversial character of the treatment and the obligatory participation of subjects. The negative statements perhaps confirmed existing attitudes. Three suggestions to control for pretest sensitization effects were given: (1) use research designs with control conditions; (2) separate the pretest phase from the posttest phase; and (3) give more emphasis to designs without pretests.

In many evaluation studies the subjects take one or more attitude measures both before and after the experimental treatment. Because of a sensitization effect of the pretest, this pretest treatment-posttest design may confound the treatment effect. Previous work suggests several sources of such bias in the posttest scores:

APPLIED PSYCHOLOGICAL MEASUREMENT

Vol. 3, No. 1 Winter 1979 pp. 25-30

() Copyright 1979 West Publishing Co.
1. The pretest may raise the curiosity of subjects and thus have a motivational effect.

2. Pretesting may orient the subject's attention selectively toward certain aspects of the treatment. For example, subjects in an educational experiment may learn what to concentrate on during their study of the instructional materials.

3. Taking a pretest engages the subject in a form of public commitment and may therefore have an inhibitory influence on subsequent attitude change.

4. The pretest items may alert the subject to the intent of the investigator and may subsequently facilitate or inhibit opinion change depending on the subject's willingness to comply with the experimental demands.

5. The information contained in the pretest may induce the subject to consider the position implied by this information. This advertising or priming effect may facilitate attitude change.

Despite the plausibility of these explanations, the empirical evidence of a pretest treatment interaction bearing on attitude change research or evaluation research is, in general, meager. Researchers often conclude that pretesting is not a serious problem and tend to dismiss special precautions to prevent or detect sensitization effects. For instance, Welch and Walberg (1970), using six cognitive and affective measures, failed 
to detect any significant pretest effects and speculated that these effects "are not serious problems when the treatment occurs in a normal classroom situation over the academic year and when test taking is part of the daily routine"' ( $p$. 613). Cowan and Komorita (1971) were also unable to show a directional effect of pretesting on opinion change. They concluded that "all the concern over sensitization may have been overemphasized and that to the extent that these findings may be generalized it does not seem necessary to use Solomon's four group design to control for pretest sensitization nor an awareness control group" (p. 439).

The present study discusses two empirical examples with less reassuring methodological implications. The first experiment sought to detect the presence of a sensitization effect in evaluating a programmed course in introductory mathematics. The main purpose of the second experiment (arising out of the first experiment) was to test the biasing effects of both positively and negatively toned pretest items on subsequent posttest scores.

\section{Experiment I}

\section{Method}

Subjects were 119 male and female first-year psychology students of the University of Amsterdam. As part of their course obligations, these freshmen had to prepare for an examination on introductory mathematics. A linear programmed textbook was used as the vehicle of instruction. Following the examination, students responded to a questionnaire concerning their attitudes toward programmed instruction. Prior to the course, approximately six weeks earlier, a random sample of 39 students completed the questionnaire as pretest. This resulted in a simple separate-sample pretest-posttest design (Campbell \& Stanley, 1966). The attitude measure for this study was adapted from an instrument constructed by Brown (1966). It had 21 items of the summated-rating format with scale points ranging from 1 (agree) to 5 (disagree).

\section{Results}

The means, standard deviations, and coefficient alpha reliability estimates are given in Table 1. They indicate that the feelings of Condition 1 students toward programmed instruction were, on the average, more positive before the course than after (means 3.47 and 3.24, respectively). Only 8 out of 39 students had more positive feelings after the course than before, whereas 28 students had higher pretest scores (nondirectional sign test: $z=\overline{3} .17 ; p=.0016$ ).

A repeated administration of the attitude measure without any experience with programmed instruction in between, however, might show a similar decrease. Condition 2 allowed the assessment of this possibility. Comparison of pretest scores of Condition 1 with posttest scores of Condition 2 should confirm the outcome of the comparison of pretest and posttest scores obtained in Condition 1. Inspection of the mean scores in Table 1 shows this confirmation to be absent. Condition 2 students evaluated the programmed method even more positively after the treatment than Condition 1 students did before (means 3.55 vs. 3.47 ). The reliability across times (pretest vs. posttest) was about the same, whereas the reliability across conditions (Posttest 1 vs. Posttest 2) was not substantially different (.818 vs. .867$)$. One has to conclude that pretesting facilitated attitude change, thus confounding the appreciation of the instructional material.

Re-examination of the items comprising the questionnaire supported this conclusion. Only 7 items referred to positive aspects of programmed instruction, the remaining 14 items alerting students to negative aspects or consequences of this instructional method. It is still not clear what would be the biasing effects of pretests orienting a subject's attention to either positive or negative treatment aspects exclusively. In line with the results of Experiment 1, it might be hypothesized that negatively toned pretest items lead to a decreased appreciation of a treatment, whereas positively toned pretest items may function to increase appreciation, or 
Table 1

Means and Standard Deviations of Pretest and Posttest Scores of Both Groups; Experiment 1

\begin{tabular}{lcccccccc}
\multirow{2}{*}{ Condition } & \multicolumn{4}{c}{ Pretest } & & \multicolumn{3}{c}{ Posttest } \\
\cline { 3 - 5 } \cline { 7 - 9 } & $N$ & Mean & S.D. & alpha & & Mean & S.D. & alpha \\
\hline 1 & 39 & 3.47 & 0.55 & .821 & & 3.24 & 0.55 & .818 \\
2 & 80 & - & - & - & & 3.55 & 0.62 & .867 \\
\hline
\end{tabular}

at least to counteract the development of negative feelings. These two hypotheses were tested in a second experiment.

\section{Experiment 2}

\section{Method}

Subjects were 162 male and female psychology freshmen of the University of Amsterdam. As part of their course obligations, these students participated in a collective testing program lasting eight days. During this test week, students responded to a large variety of personality tests, opinion questionnaires, and other measures. The first measure of the 1977-1978 test week consisted of an attitude measure of 13 statements on the test week itself. There were two versions. One version contained items referring to positive aspects (e.g., The organization of the test week is professional); the other version contained negative items (e.g., The organization of the test week is not professional). A random sample of 38 students took the positive version as a pretest and, eight days later, as a posttest. The negative version was administered to a random sample of 38 students, both as a pretest and as a posttest. As a pretest, the remaining 86 students filled out a 13 -item control questionnaire of similar length, format, and layout on ecological issues within the laboratory building. Fifty of these students subsequently took the positive test week measure as a posttest, whereas a random sample of 36 students completed the negative version. This procedure resulted in a double separate-sample pretest-posttest design (see Table 2).

The attitude measure was constructed for this study. All items were of the summated-rating format with scale points ranging from 1 (agree) to 7 (disagree).

\section{Results}

Before the statistical analysis, the reactions to the items of the positive version were rescored, response options agree (1) and disagree (7) now being labeled 7 and 1 . On both versions of the attitude measure, a high score then stood for a positive attitude and a low score for a negative one. Table 3 reports the means, standard deviations, and alpha reliability estimates.

\section{Table 2}

Experimental Design of Experiment 2

\begin{tabular}{llccl} 
Condition & $\mathrm{N}$ & Pretest & Treatment & Posttest \\
\hline 1 & & & & \\
2 & 38 & positive & yes & positive \\
3 & 50 & no & yes & positive \\
4 & 38 & negative & yes & negative \\
\hline
\end{tabular}


Table 3

Means and Standard Deviations of Pretest and Posttest Scores of Four Groups; Experiment 2

\begin{tabular}{|c|c|c|c|c|c|c|c|}
\hline \multirow{2}{*}{ Condition } & \multirow[b]{2}{*}{$\mathrm{N}$} & \multicolumn{3}{|c|}{ Pretest } & \multicolumn{3}{|c|}{ Posttest } \\
\hline & & Mean & S.D. & alpha & Mean & S.D. & alpha \\
\hline 1 & 38 & 3.35 & 0.72 & .852 & 2.79 & 0.85 & .867 \\
\hline 2 & 50 & - & - & - & 2.38 & 0.91 & .880 \\
\hline 3 & 38 & 4.80 & 0.70 & .825 & 4.14 & 0.91 & .813 \\
\hline 4 & 36 & - & - & - & 4.04 & 0.71 & .823 \\
\hline
\end{tabular}

The results of univariate $t$ tests (one-tailed) indicate that students were appreciably less positive towards the treatment afterwards than before (Condition $1: t=-4.695, d f=37, p<.001$; Condition $3: t=-5.238, d f=37, p<.001$ ). This phenomenon cannot be explained by a pretest effect of the first attitude measurement, since comparison of pretest means of Conditions 1 and 3 with Control posttest means confirmed this outcome (Pretest 1 vs. Posttest $2: t=$ $-5.353, d f=86, p<.001$; Pretest 3 vs. Posttest $4: t=-4.557, d f=72, p<.001)$. It is possible, however, that the negative pretest acted as a device stimulating the development of negative feelings, whereas the positive pretest may have counteracted such development. The results support only the second hypothesis. Giving answers to a set of positive attitude items seems to have functioned to inhibit subsequent attitude change (Posttest 1 vs. Posttest $2: t=-2.160, d f$ $=86, p=.03$ ), whereas responding to the negative pretest items did not result in less positive reactions than without pretesting (Posttest 3 vs. Posttest $4: t=-.515, d f=72, p=.61$ ). In addition, it was again verified that the reliability across times and conditions was the same. As shown in Table 3, the reliability estimates across times (Pretest 1 vs. Posttest 1 and Pretest 3 vs. Posttest 3) were about the same. The same conclusion was reached for the reliability across conditions (Posttest 1 vs. Posttest 2 and Posttest 3 vs. Posttest 4 ), the differences between the coefficient alpha reliability estimates being only trivial.
An unexpected finding of the study was the absolute magnitude of the meañ scores. Suppose a curriculum researcher was utilizing the attitude measure for evaluative purposes. It is clear from the posttest results in Table 3 that the conclusion would be different if based on the positive version rather than on the negative version. Still, it is customary, and hardly avoidable, to interpret both an agree response to a positive statement and a disagree response to a negative one as indicative of a positive attitude. Although the findings of this study are limited, the implications for evaluative studies might be formulated as follows: A negative conclusion as to the attitudes toward the treatment becomes plausible when a set of positive statements is filled out by an unpretested group of subjects, whereas a neutral or even mildly positive conclusion seems plausible when the evaluation study is designed as a standard pretest-treatment-posttest design with an attitude measure consisting of negative statements as criterion.

\section{Discussion}

The results of both experiments reported in this paper indicate a clear effect of pretesting on subsequent posttest results. In Experiment 1, the pretest led to a decreased appreciation of the treatment, whereas in Experiment 2 a pretest referring to positive treatment aspects counteracted the development of negative feelings. There is, however, a question on the absence of a pretest effect of the negative attitude measure 
used in Experiment 2. This unexpected outcome may spring from the context in which the experiment was conducted. As stated before, participation was compulsory. The mandatory character of the test week was strongly opposed by the local student movement and led to active attempts to rouse popular feeling against this requirement. The negative pretest statements perhaps confirmed prevailing feelings. The positive version presented subjects with another point of view, contrary to the prevailing prejudices. The results suggest that these pertinent positive statements embedded in the pretest partly counteracted the development of even more negative feelings than were initially present.

Previous work suggested that several features of the usual attitude measure and the existing circumstances should be considered in interpreting pretest sensitization effects. One such feature concerns the possibility that pretests and posttests did not entirely measure the same construct. An attempt was made to verify this question by examining the pretest-posttest correlations corrected for attenuation. However, since the control subjects in both experiments were not given a pretest, it was not possible to examine this issue in a completely satisfactory manner. For Experiment 1 a pre-post correlation of .82 was obtained; for Experiment 2 the coefficients of correlation were .68 (Condition 1) and .67 (Condition 3). The data support the idea that it is somewhat dangerous to interpret studies of the kind discussed here in a completely general way.

A second feature concerns the external commitment of subjects. Lana (1966), for example, believes that signing one's name to a questionnaire implies a form of public commitment which may have an inhibitory influence on attitudinal change. Quite contrary to Experiment 2, which was run anonymously, subjects of Experiment 1 signed their names to the questionnaires; the outcome of this experiment thus does not support Lana's assumption. Nosanchuk, Mann, and Pletka (1972) obtained results that also showed subject commitment to be of no influence.

A third feature is that as a result of pretesting, subjects become aware of the intent of the experimenter. Depending on the willingness of the subjects to play "good subject" (Orne, 1969), the reactions may be contaminated either in line with the alleged intent of the experimenter or in the opposite direction. In both experiments, subjects were probably aware of the evaluative purposes of the attitude measure. It is doubtful, however, that they were aware of the more specific research hypotheses. Moreover, the willingness to play the role of good subject is usually associated with volunteer status (i.e., Rosnow, Holper, \& Gitter, 1973). As indicated above, the students in the present studies participated on a non-voluntary basis.

An interpretation of the experimental results as an orienting effect of pretest information on the subject's attention and motivation seems more plausible. It may, of course, be argued that the sensitization effects obtained were specific for the information and topics contained in the pretest items. This interpretation cannot be excluded, since both experiments used the same measure as pretest and posttest. Further research is needed to see if the effects are of a general kind or are restricted to pretest content. Since identical pretest and posttest measures are the rule rather than the exception in evaluation studies, it seems a methodological requirement to take proper precautions to control for pretest sensitization. One possibility is to use research designs that control for this effect. Another possibility is to separate the pretest phase from the posttest phase of measurement (see Cowan \& Komorita, 1971). Finally, although there are reasons to prefer pretesting to a randomized design without a pretest (i.e., Lana, 1969, p. 122), the results of these experiments support suggestions to put more emphasis on research designs without pretests. Most evaluation studies using large enough subject pools can usually assume that randomization will result in compar- 
able groups of subjects in the separate experimental conditions.

\section{References}

Brown, B. R. An instrument for the measurement of expressed attitude toward computer-assisted instruction. In H. E. Mitzel \& G. L. Brandon (Eds.), Experimentation with computer-assisted instruction in technical education. University Park, PA: Pennsylvania State University, 1966.

Campbell, D. T., \& Stanley, J. C. Experimental and quasi-experimental designs for research on teaching. Chicago: Rand McNally, 1966.

Cowan, G., \& Komorita, S. S. The effects of forewarning and pretesting on attitude change. $E d u$ cational and Psychologica! Measurement, 1971, 31. 431-439.

Lana, R. E. Inhibitory effects of a pretest on opinion change. Educational and Psychological Measurement, 1966, 26, 139-150.

Lana, R. E. Pretest sensitization. In R. Rosenthal \& R. L. Rosnow (Eds.), Artifact in behavioral research. New York: Academic Press, 1969.

Nosanchuk, T. A., Mann, L., \& Pletka, I. Attitude change as a function of commitment, decisioning, and information level of pretest. Educational and Psychological Measurement, 1972, 32, 377-386.

Orne, M. T. Demand characteristics and the concept of quasi-controls. In R. Rosenthal \& R. L. Rosnow (Eds.), Artifact in behavioral research. New York: Academic Press, 1969.

Rosnow, R. L., Holper, H. M., \& Gitter, A. G. More on the reactive effects of pretesting in attitude research: Demand characteristics or subject commitment? Educational and Psychological Measurement, 1973, 33, 7-17.

Welch, W. W., \& Walberg, H. J. Pretest and sensitization effects in curriculum evaluation. American Educational Research Journal, 1970, 7, 605-614.

\section{Acknowledgments}

I thank Professor F. N. Kerlinger for his comments on an earlier draft of the manuscript and J. van Heerden for his help in designing the second study.

\section{Author's Address}

Joh. Hoogstraten, Psychologisch Laboratorium, Universiteit van Amsterdam, The Netherlands. 